\title{
MeASURING THE ImPACT OF StUdent Led TUtorials ON First YEAR STUDENTS' LEARNING OUTCOMES
}

\author{
Sohad Kadhum, Brad Buckham and Ben Nadler \\ Faculty of Engineering, University of Victoria, Mechanical Engineering Department, Victoria BC, Canada \\ Corresponding Author: skadhum@uvic.ca
}

\begin{abstract}
ENGR 141: Engineering Mechanics is a foundational course in the UVic Engineering Faculty that serves all of the engineering degree programs: biomedical, civil, mechanical, electrical, computer and software. Between the 2013 and 2014 offerings of the course, the ENGR 141 population grew dramatically, by well over 50\%, necessitating changes in the course structure and methods of student assessment. In addition to addressing logistical challenges, the changes were designed to develop the students' confidence in their ability to wield fundamental mechanical principles independently and in peer-to-peer working environments. This was done by repurposing the tutorial sections of the course to create student driven exploration, analysis and solution of complex three dimensional mechanics problems.

A series of 22 problems lying outside the domain of the assignment problem sets were addressed-two in each week of the tutorials. The assignments and midterms problems were constructed so that the impact of tutorial work on students mastery of the course Intended Learning Outcomes could be extracted.

Under the new tutorial format, instructors monitored group dynamics, helped troubleshoot and provided encouragement. Presentation of solution strategies were made by select student groups each week. The current work describes the motivation for the changes made, observations made at implementation and some preliminary results from analyses of the impact of the new course structure on student mastery of the course learning outcomes. Important conclusions are that the student-led tutorials should be accompanied with additional instructor contact hours that provide opportunity for students to receive tutelage on a one-to-one basis and that individual testing should stress the procedures and tools emphasized in the tutorials.

In addition, students found that assessments made through multiple choice testing contradicted values and principles being stressed in the tutorial and seminar sessions.
\end{abstract}

Keywords: Engineering Education, Mechanics, Statics, Student-Led Tutorials, Student Retention, Seminar Series, Questioning Technique.
Students' Led Tutorials, Outcome Based Teaching and Learning, Students' Mastery of Intended Learning Outcomes, Large Classrooms, First Year Education, Education Research Methods, Integrating Research and Education, Assessment of Student Learning.

\section{INTRODUCTION}

Engineering 141 (ENGR 141), Engineering Mechanics, is an introduction to mechanics that serves all of the University of Victoria's (UVic's) engineering programs: biomedical, civil, computer, electrical, mechanical and software. The course deals with the concept of static equilibrium as applied to rigid bodies, structures and simple machines. Similar courses are found in every Canadian engineering program, but the course does have some particular characteristics. First, structural analysis (trusses, beam VM diagrams, frames and machines) is included in lieu of particle dynamics. Second, the course is a core component across all disciplines leading to a highly variable level of personal interest across the student population.

The content of ENGR 141 is summarized by the student learning outcomes in Table 1 below. The course provides an overview of Cartesian vector notation, basic vector operations and three-dimensional vector mechanics (dot and cross products, projections, forces and moments, etc) and then applies these foundational concepts to a wide variety of static equilibrium problems. Students learn to form free body diagrams and the associated equilibrium equations and use these tools to determine certain forces and moments acting on and within rigid bodies, and structures and machines composed of rigid components, that are in equilibrium.

The primary pedagogical challenge in ENGR 141 is not in the dissemination of mechanical principles, but is the development of professional traits in the students. Can the students apply basic concepts and tools in a logical and concise manner to solve three-dimensional mechanics problems? Can this process be communicated clearly? Will the students evaluate their own results, and the work of others, critically? In the Faculty, it is felt that the work habits acquired in ENGR 141 affect student performance 
in subsequent years of the program, as well as student retention in the Engineering programs.

\subsection{Historical Context}

Traditionally, the ENGR 141 instructional components include lectures delivered by the course instructor, and instructor driven tutorials delivered by two sessional instructors. In addition to lecture and tutorial contact hours, a help centre was established in 2007 to provide opportunity for drop in assistance. Between 2008-2013 (inclusive), the help centre was typically open for 8-9 hours per week and was staffed by a teaching assistant (TA) or one of the course instructors. The help centre provided opportunity for student driven drop-in assistance on a one-to-one basis.

\begin{tabular}{l|l}
\hline \hline 1 & $\begin{array}{l}\text { Sketch three-dimensional Cartesian reference frames, force } \\
\text { vectors and moment vectors. }\end{array}$ \\
\hline 2 & Label sketches and diagrams using proper vector notation. \\
\hline 3 & $\begin{array}{l}\text { Assign reference points and calculate the moment of a force } \\
\text { relative to those points. }\end{array}$ \\
\hline 4 & $\begin{array}{l}\text { Combine several forces and moments to form simpler } \\
\text { equivalent force-couple systems. }\end{array}$ \\
\hline 5 & $\begin{array}{l}\text { Identify the forces and moments acting on a rigid body and } \\
\text { draw the corresponding free body diagram (FBD). }\end{array}$ \\
\hline 6 & Apply the method of statics to FBDs. \\
\hline 7 & $\begin{array}{l}\text { Manipulate algebraic equations of equilibrium within the } \\
\text { method of statics }\end{array}$ \\
\hline 8 & $\begin{array}{l}\text { Divide a structure into sub-assemblies that can be analyzed } \\
\text { using method of statics. }\end{array}$ \\
\hline 9 & $\begin{array}{l}\text { Label, calculate and assess internal forces and moments in } \\
\text { trusses and beams }\end{array}$ \\
\hline 10 & $\begin{array}{l}\text { Recognize statically determinant and indeterminant } \\
\text { mechanics problems by observation of FBDs. }\end{array}$ \\
\hline 11 & $\begin{array}{l}\text { Organize multiple FBDs in the solution of impeding motion } \\
\text { problems. }\end{array}$ \\
\hline 12 & $\begin{array}{l}\text { Judge whether the static equilibrium assumption is possible } \\
\text { based on solutions to equilibrium equations. }\end{array}$ \\
\hline 13. & $\begin{array}{l}\text { Calculate the location of centroids of lines and areas using } \\
\text { single variable calculus. }\end{array}$ \\
\hline
\end{tabular}

Table 1. The ENGR 141 learning outcomes. The course is focused on instilling professional habits in the solution of introductory level mechanics problems.

For the past decade, the course has been well thought of by students yet classified as one of the hardest courses in UVic Engineering common first year and failure rates have traditionally varied between $20-30 \%$. However, students who arrived at UVic with high motivation, good work habits, and clear professional goals tended to do very well in the course. In addition, the instructional teams' commitment to running the help centre gave opportunity for personal assistance and mentorship which offset some of the rigours associated with the individual assignment and test course components.

1.2. Problem Statement Since 2008 several disturbing trends in ENGR 141 student behaviour have been observed. These include: 1.Widespread use of nonrefereed materials from external sources downloaded from the internet (solution manuals, old marked exams, graded past student work), 2. Very low uptake of the help centre in 2012 and 2013. 3. Decreasing attendance at the tutorial sessions.4. Low averages on course testing components (quizzes, midterms and final exam). 5. Low-quality assignment submissions that ignore the tools and procedures championed in the lecture and tutorial periods. Of the above, the drop off in attendance at the ENGR 141 help centre was most concerning. For example, in 2012, most days saw only 3-5 people show up in a class of over 250 people. From assignment submissions, it was readily apparent that students were turning to on-line solutions and worked examples rather than working with an instructor at the help centre to develop their own solution strategies. By foregoing the opportunity to practice the execution of solution procedures independently, students were tending, we believe, to compartmentalize mechanics problems; students could solve problems of a very particular type using a particular procedure, but could not extend the components and tools of such solutions to other types of problems. The traditional method of tutorial instruction, instructor led presentation of example problem solutions, appeared to reinforce this mode of learning. Table 2 shows the grades from the quizzes and exams of 2008-2012 that is evidence to the widespread inability of students to solve exam questions for which students hadn't been provided explicit solutions for. In 2012 and 2013, tutorial attendance was notably lower than past years.

\begin{tabular}{|l|c|c|c|c|c|} 
& 2008 & 2009 & 2011 & 2012 & 2013 \\
\hline \hline Quiz \% & 60.2 & 57 & & 69.5 & \\
\hline Midterm \% & 60.1 & 59.7 & & 59 & \\
\hline Final \% & 52.2 & 59 & & 58 & \\
\hline
\end{tabular}

Table 2. Class average grades for individual testing components of ENGR 141 in 2008, 2009 and 2012. In the 2010-2011 school year, ENGR 141 was moved from the fall to the spring term - hence there was no offering in 2010.

Concerns of declining student engagement with the course instructors and the course material were heightened in the fall of 2013 when ENGR enrollment grew dramatically. Figure 1 shows the ENGR 141 population from 2008 to 2014 - between 2013 and 2014, enrollment jumped by over $50 \%$ to over 400 students. 
1.3 Objectives Given the behavioural trends observed over the previous 5 year period, and the possibility of increased course enrollment creating even greater student anonymity and detachment, changes needed to be made to the structure, content and assessment procedures of ENGR 141 in order to:1. Re-engage students with course material, the course instructors and their peers. 2. Improve the ability of students to manipulate basic mechanics principles to solve a variety of problems. 3. Provide forum for the students to demonstrate their own capabilities and witness the capabilities of their peers. 4. Enforce the value of independent critical analysis over guided execution of rote learning.

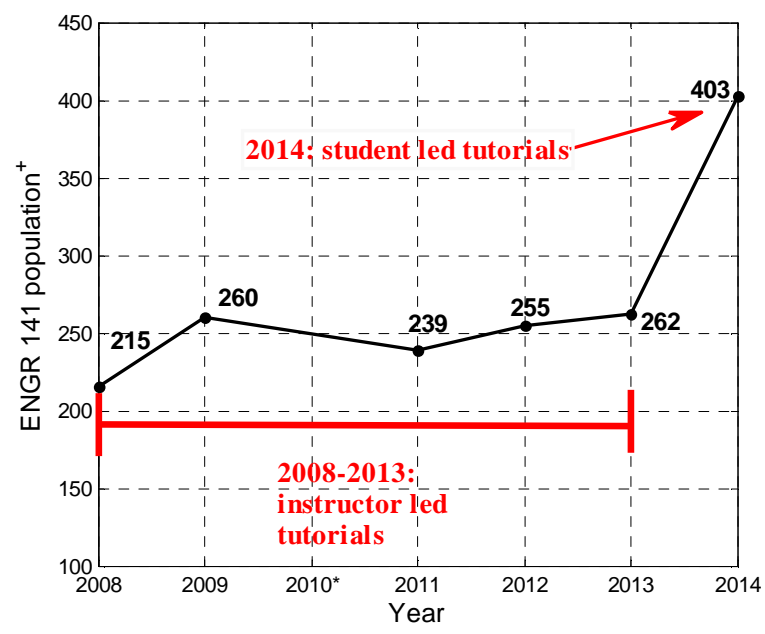

Figure 1. ENGR 141 population between 2008 and 2014 (inclusive). Numbers given are for term end (final exam attendees). In 2014, opening day enrollment was 450 students. The dramatic increase in population 2014 necessitated changes in course structure and execution.

\section{CURRICULAR DEVELOPMENTS Working}

within the span of the four month term preceding the spring 2014 offering of ENGR 141, the authors worked to design course components that would complement the existing lecture contact hours, with formalized (scheduled) student driven sessions that would force students to engage with their peers and to apply mechanics principles presented in the lecture sessions. In these formal sessions, we wanted to ensure that there was no opportunity for the students to draw upon web based resources (existing solutions, prior student work). Rather, we wanted to encourage individual and group based discovery in order to develop self-confidence within the student population.

Rather than disturb the lecture content and methods, which have been traditionally well received by the students, the tutorials were repurposed as the venue for the student driven course experience. Tutorials have long been seen as an opportunity to motivate and engage students, and a venue to provide constructive feedback [1]. However, prior to 2014, we have seen that the traditional delivery of tutorials (students act as passive learners and the instructor determines the method of attacking a particular problem) is leading to low attendance. This is in part due to increased tutorial section sizes: we had approximately 60 students in each tutorial section, which limited the ability to provide individual feedback. However, the prevalence of on-line learning materials, both regulated and unregulated, also drive low tutorial turnouts. These materials are perceived by the students to be equivalent to that delivered in the tutorials and offer immediate gratification. Unfortunately, the use of on-line learning material (especially unregulated materials) is a one way flow of information the student takes from the source at his leisure without being directed or challenged by the source.

In the new tutorial sections, challenging purpose-built mechanics problems were designed that would require sequential application of course concepts to solve. The majority of problems could not be completely solved inside the tutorial sessions. Rather student teams would work on the strategy to solve the problem. This would include the

Literature and studies suggested that the use of lectures is a one way of passing the information from the expert in the field to the students [2,3, and 4]. During the lectures, student participation is limited to asking questions and getting clarification on some aspects, as the tutorials were set to complement the lectures (Biggs and Tang 2011).

\subsection{Resources}

In Spring 2012, the authors of this paper ran four experimental sessions of student led tutorials. At the end of each session, we asked for anonymous feedback where the students shared with us their experience with this experiential tutorial session and voiced what could be done differently. Most of them indicated that they learned more in this format and they wished all the tutorials could be done this way. In Spring 2013, we were granted the Curriculum Development Grant. We designed a starting and a final questionnaire that was used to gauge student prior knowledge and the impact of conducting tutorials on their confidence and Learning outcomes. Majority of the funds were used to fund the time in the seminars - was there for the vast majority of the hours.

\subsection{Curriculum Innovation - Goals}

Create a workspace for the students to reflect on their learning process and receive constructive feedback on their daily progress through the term we added the 
Seminar Series. Replacing the ineffective help centre, the Seminar Series provided interaction with the students through asking them questions that geared to promote their own thinking. With each question from the students we propose another question to guide them through the learning process. Psychology studies concerning human cognitive abilities [5] and learning and teaching studies [6] are in favour of this approach.

\subsection{Formative and Summative Assessments}

Through the term we conducted several formative assessment through the new course structure by observing the Students' Led Tutorial work, presentations of the Tutorial Problems, and final submission of group work. At the seminar sessions, we received instant feedback on the instructional activities, the students learning activities, and we implemented any needs directly.

After the first midterm, we also asked for an anonymous feedback from the students through the Tutorial session to give them the chance to give a feedback freely. We incorporated most of their suggestions and needs through the rest of the term.

The PI and RA returned to the ENGR 141- Engineering Fundamentals I course at the end of the term to present the research for a second time and return the starting questionnaires at the beginning of the term. Then will conduct the final questionnaires. Participants' anonymity will be protected by a code created before completing the starting questionnaires. Students will be asked to sign the consent form a second time in order for the researchers to obtain proper on-going consent for the research.

\section{IMPLEMENTATION}

A series of 22 challenging mechanics problems that are slightly outside the conventional domain of the course assignment problem sets were addressed - two in each week of the tutorials.

The assignments and midterms problems are constructed so that the impact of tutorial work on students' mastery of the course Intended Learning Outcomes could be extracted. We monitored the students' progress through self-assessment of their tutorial projects where they record the steps taken to analyze their assigned projects, the identification of their knowledge and gaps if there is any, and the steps taken to fill these gaps.

We measured the engagement of the students in the course by keeping an attendance record of the Seminars sessions. In addition to the impact metrics, we mentioned above, a starting and a final questionnaire were designed and used to help gauge student prior knowledge and the impact of conducting tutorials on their confidence and Learning outcomes.

The current inquiry is to measure the impact of new student led tutorials on the students' learning outcomes.
Within the student led tutorials, facilitators observed the group dynamics and ensured that the stages of Tuckman's Team Development Model are followed. Students were provided with the course different components, lectures, Online and Hard Copy Assignments, Students' Led Tutorials, Seminar Series, midterms and final examination and other scheduling provided in this course outline.

\subsection{Lectures}

To accommodate the 450 students, we had two sections of the lectures were two instructors were delivering two lectures of an hour and half three hours per week. Lecture hours were devoted to introducing, reviewing, and discussing the course material as it is presented in the required textbook [7].

\subsection{Online and Hard Copy Assignments}

To assess the student pro formatively, a sets of online assignment using Pearson's Mastering Engineering website which is required in order to complete the ENGR 141 assignments and access additional on-line resources posted by the course instructor (including lecture notes and sample problems that are covered in the lecture and tutorial periods). The Mastering Engineering website also provides students with access to an on-line study area that includes several additional example problems (some presented in video format) that are organized by textbook chapter.

Success in this course results from practicing as many problems as possible and the assignments represent a baseline level of engagement with the course material. Students were encouraged to use the seminar times to attempt additional problems - the skill level one attains in ENGR 141 is directly dependent on the number of problems from the required textbook that are attempted on one's own accord.

Nine problem sets, each having five questions, plus some extra credit problems, will be assigned over the course of the term. For each problem set, only 1 of the assigned questions will be completed and submitted in hardcopy.

The remaining 4 assignment problems are completed on the Mastering Engineering on-line system ("end-ofsection" problems in the Mastering Engineering system). The Mastering Engineering problem numbers correspond to the problems in the required textbook.

Additional Mastering Engineering "tutorial" style problems can be completed in some assignments for extra credit. Tutorial problems are staged and hints were available if requested. Grades for all Mastering Engineering problems are assigned based on how many hints students elect to use, how many times the problem is attempted incorrectly, etc. The grading policy can be viewed on-line for each assignment. Before students can attempt any of the Mastering Engineering assignment 
problems, a Mastering Engineering tutorial has to be completed. Access to the assignments will only be unlocked when this tutorial is completed.

\subsection{Students' Led Tutorials}

There were nine Students' Led Tutorial (SLT) sections for ENGR 141 with approximately 50 students in each tutorial section, the tutorials began in the first week of class. The weekly ENGR 141 tutorials are a mandatory course component and Teaching Assistants who are graduate students who acted as facilitators of learning observed them. Students were encouraged to attend their specific section in order to ensure a proper distribution of students. Eight of the SLT were observed by two TAs in the exception of the ninth SLT section, one TA was observing that section.

To ensure the success of the new curriculum development, most of TAs were carefully selected based on experience and motivation. A short training was provided to the TAs that was derived from the Instructional Skills workshop [1,3,6,and 8].

The tutorial structure and content was discussed at the first tutorial session of each tutorial section. The students' groups were formed using the spectrum of difference of the students' self reported experience working in the group. It was a random groups' replacement and most of the group's members were meeting each other for the first time. We used the first tutorial session to form the groups, and did other activities to find the ground rules of working in the groups and responsibilities. we also shared and discussed the group dynamics, and the stages of Tuckman's Team Development Model [1, and 3]. We also touched on other SLT projects managements, the tutorial group work submission, students were responsible for ensuring that identification (including tutorial section, names and student numbers) were provided for those individuals who contributed to the submission. we encouraged the students to use the other course component, the Seminar Series.

Students' groups needed to review the weekly two tutorials problems before their tutorial sessions. At the tutorial session, two groups were each assigned a different problem to work on and present. The rest of the groups can choose one of the problems to work on. All of the 11 groups will have 20 minutes to work on their problem. We then collect all the drafts before the starting of the presentations. The first group presenting had 15 minutes, 10 minutes presentation time plus 5 minutes question and answer time. The second group presenting had 15 minutes, 10 minutes presentation time plus 5 minutes question and answer time. To allow each group a chance for reflection and to consider ideas presented by other groups, a final draft hardcopy solution of the tutorial problem were submitted one week after the tutorial session.

\subsection{Seminar Series}

The seminars offered students an opportunity to engage the course instructors on a one-to-one basis and to ensure that students are able to make steady progress on assignment and tutorial problems. Students are encouraged to work in groups at the seminars provided they do not disrupt the seminar session. At the seminars, instructors will address common questions on the board for the benefit of all seminar attendees. While attendance at all the seminars is not mandatory, participation in the seminar series does constitute a small portion of each student's overall grade.

The course instructors and TAs took attendance at the seminars. Students did not have to attend all the seminars nor did they need to attend complete sessions - a half hour of work (discussion with instructors, individual work, group work, etc) at the seminar will count as an "attended session." For each attended session, students will earn $0.5 \%$ towards their final grade. Students who elect to present a problem solution to the seminar attendees or to lead discussions on problem solutions with their peers will be provided additional marks, at the instructors' discretion, towards their seminar participation grade.

Taking into consideration the different courses that the first year students are taking, we looked into their schedule and offered different three different options on Tuesdays, Wednesdays, and Thursdays of each week. The total tutorial time was eight hours and a half. At the end of the term, we scheduled additional sessions before the final examination. The Seminar Series were held at the UVic McPherson Library.

\section{RESULTS and DISCUSSION}

Our summative feedback was through the online assignment submission which give us idea on the students' individual progress. Since it was limited to the final answer we resort to the hard copy submission to evaluate the learners' progress. The first midterm gave us a somewhat indication but not a complete sense of student progress because we used multiple-choice format, but the average was high. We raised the bar higher at second midterm and consequently we had a lower average.

Taking all of these formative and summative feedbacks, the final exam was designed into two components that are equally weighted, multiple choice problems and three hand written question. The overall results were good.

We are happy with the quality of the student work and the submission of their work. The Student Led tutorials were a great change that we made to the course structure. 
It was a very dynamic environment ere the learners came prepared and ready to take the challenge of analysing, solving, presenting, asking questions, and addressing their peer questions. The seminar series was a great way of creating a workspace that the students own and were proud of it. Different leaning activities were happening at the same time and it is a student centered learning environment. The motivation was high and that helps bring the highly motivated students closely to the students who show low interest in the subject. In the end, the learning process was clearly shown and observed. We were very successful in setting the students ready for their engineering education.

In the Spring term 2014, ENGR 141, Engineering Fundamentals I, were taught to 450 students. The course is a foundational one at the University of Victoria Engineering Faculty. Skills and knowledge acquired in this course affect student retention and performance in subsequent years of the program. The students participated voluntarily and anonymously in questionnaires entitled the Student's led Group Tutorials Development that had been designed to measure the impact of student led seminars (group tutorials) on the students' learning outcome. The questionnaires reflect the teaching goals; it helped the students pay attention to the different components that has been introduced to the ENGR 141 curriculum.

The starting questionnaire, which was filled at the beginning of the term in January 2014, touched on the Student's Led Group Tutorials work and the Seminar Series that were planned for the course. Also it touched on the students' personal motivation and why they are about to pursue a study in Engineering. The final questionnaire that was completed at the end of term in April 2014 was an excellent tool to encourage the students to reflect on their own performance, the learning objectives of the course, and the practical application of the information they learned and worked on.

Figure 2. shows the high impact that the students' led tutorials has on their learning activities, these results are a student self assessments through the starting and final questionnaire.

Our Inquiry Question: Will student led seminars(group tutorials), involving presentation of group work and discussions, facilitate the students' abilities to apply the fundamentals engineering concepts and theories in complex, but practical, applications while also increasing their retention of basic solution processes? Continuously, the students reported that the new model encouraged them to explore different approaches of solutions and to be engaged in the discussions.

Through the course, the focused was on the students as the main learners. By promoting and modeling the student led seminars, we has increased students motivation

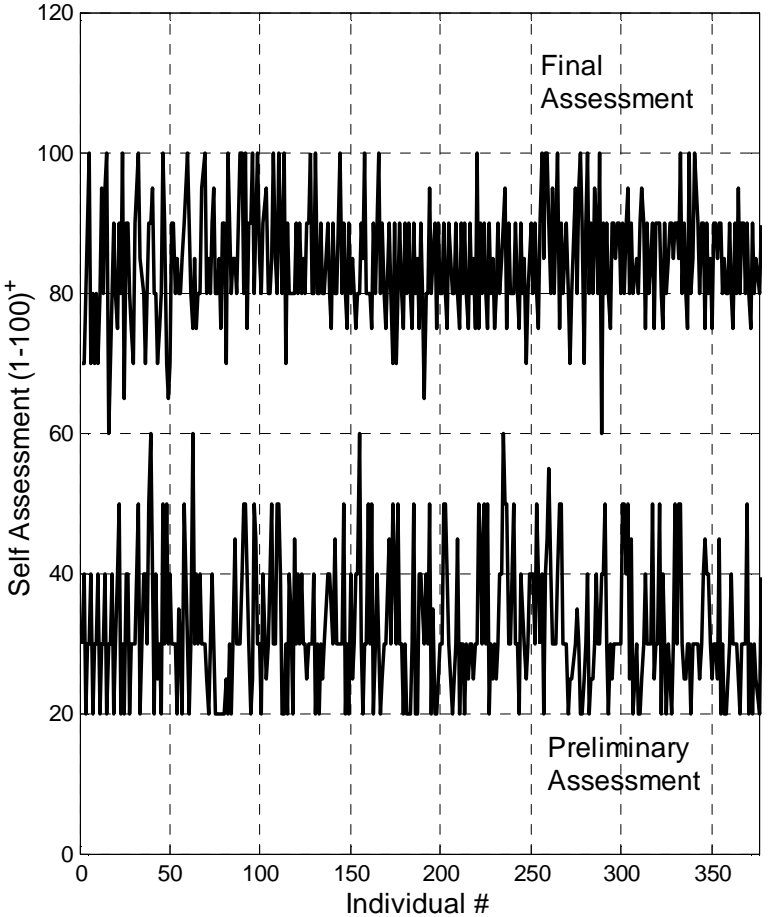

Figure. 2. The impact of Student Led Tutorials on Students' Learning Outcome. The question was: Did student led seminars (group tutorials), involving presentation of group work and discussions, facilitate the students' abilities to apply the fundamentals engineering concepts and theories in complex, but practical, applications while also increasing their retention of basic solution processes?

With the new model of the Seminar Series that was held at the UVic McPherson Library, the students were provided with a workspace where they can meet their group members, work on their assignments or tutorial projects, review lectures material and examples, read the text book content and work on the examples, present work to other fellow students, work on other recourses on the field of statics. Students were there also to explore different concept with the continuous input of the TAs and the instructors. It was a very dynamic environment and most of the time it is full and students would migrate over to other areas in the Library. By extending the learning time outside of the existing course venues, the students are putting the course concepts into their professional growth, which helped create in them the passion to be lifelong learners. We felt a sense of engineering community that is working together, it was one of the most valuable experiences that we had and we wish to see at the near future more courses adapting this model.

and capacity for learning. This approach engaged the students in different short-form mechanical projects, derived from wide varieties of situations on campus and in 
the community to explore the practical application of fundamental mechanics concepts and theories introduced in the regular lecture.

The new structure of nine students led tutorials sections and each session has 50 students that were put in 11 groups of 4 to 5 students enabled the students to get the one on one interaction with the course instructional team. The students were not just an individual, they were part of the course and they were recognized and identified by their participation, abilities, needs, and contribution. The students were encouraged to give feedback throughout the course, the regular check up made them feel important and assured them that their learning needs were met. Most of the student suggestions were applied after each feedback session to enhance their experience. The students eagerly looked forward to the next challenge through the tutorial problems and the different concept that they were about to uncover.

Figure 3. shows the grades' based comparison between the instructor led tutorials and the students' led tutorial. Examining the figure we can conclude that the new approach is having a wide impact on the students' performance. We are happy with the quality of the student work and the submission.

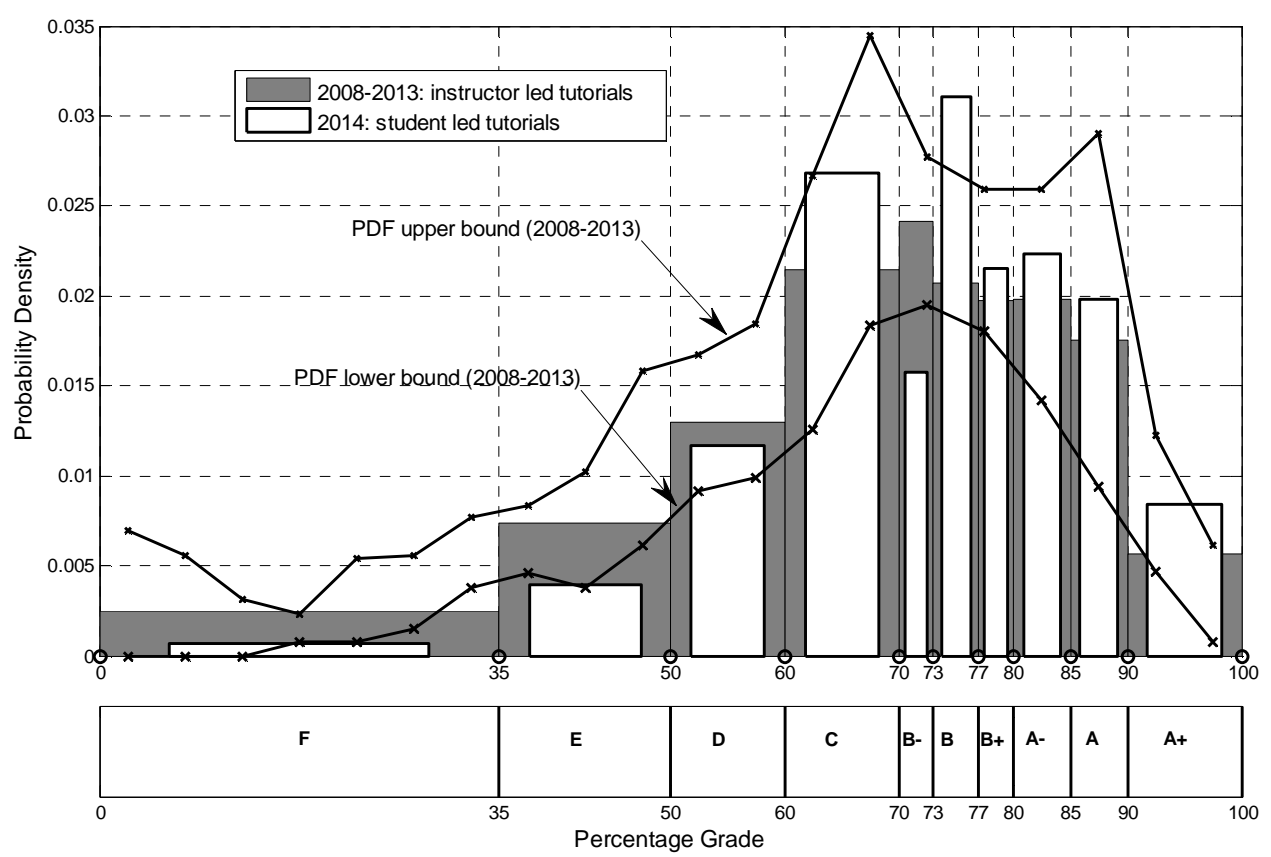

Figure 3. Grades' based comparison between the Instructor Led Tutorials and the Student Led Tutorials. The failing and incomplete grades for the new model were lower than the Lower Probability Density Function (LPF.) While the B+ and A+ Exceeded the Higher Lower Probability Density Function (HPF.) Noticeably, the B- grades failed below the LPF.

The students felt that they are capable of achieving any goal that they set for their selves in the condition of giving it what it takes to accomplish that. The students were encouraged and motivated to be immersed in that experience of keep on practicing until they achieve the requirements. When we reflect back on our path through the last four months we feel very proud of what we accomplished and the information we learned.

At the end, the new model helped the students to generate connecting paths to their future careers through the involvement in the development stages of the learning process. They walked away with an enriched experience, sense of pride and that will help them in setting their future career paths. The students had a valuable learning experience and they will thrive on for a long time. We were able to created in students the passion to be a long life learners. 

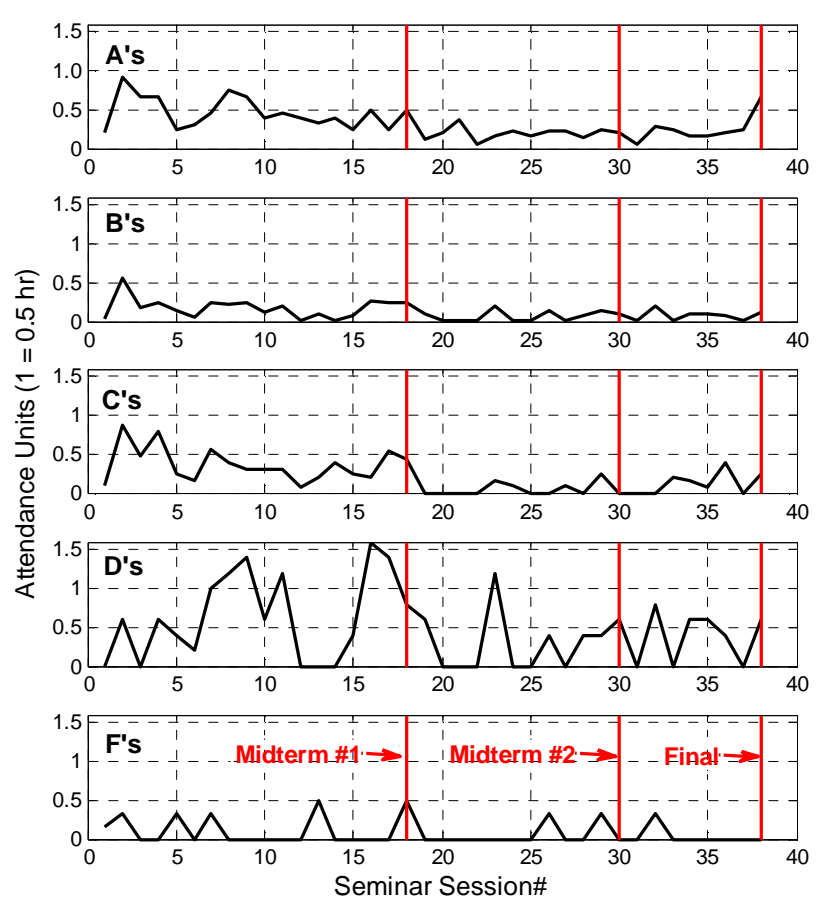

Figure 4. Grades' based comparison of students Attendance of the Seminar Series through the term. Special observation is made prior to the midterms and the final examination.

\section{CONCLUSIONS}

The outcomes of this research may assist and prepare UVic engineering students for their professional journey by developing confidence in their ability to wield fundamental mechanical principles. This will occur through student driven exploration, analysis and solution design for a complex three-dimensional mechanics problem in the new seminars sessions. Instructors of ENER 141- Engineering Fundamentals may gain insight in aspects of the course.

The anonymous results of this study will be shared with the ENER 141- Engineering Fundamentals I course instructors, administrators and future ENER 141Engineering Fundamentals I course instructors. The anonymous result may also be used by the researchers, the Mechanical Engineering Department, the Faculty of Engineering for the use on Faculty of Engineering website, in scholarly journal articles, and at professional conferences.

The results was presented to the faculty of Engineering to showcase our work to inspire and motivate others to adapt the student led tutorials approach into other Engineering courses. Venue for such presentations was the Faculty of Engineering Teaching Retreat.

The new structure of nine students led tutorials sections and each session has 50 students that were put in 11 groups of 4 to 5 students enabled the students to get the one on one interaction with the course instructional team. The students were not just an individual, they were part of the course and they were recognized and identified by their participation, abilities, needs, and contribution. The students were encouraged to give feedback throughout the course, the regular check up made them feel important and assured them that their learning needs were met. Most of the student suggestions were applied after each feedback session to enhance their experience. The students eagerly looked forward to the next challenge through the tutorial problems and the different concept that they were about to uncover.

The students felt that they are capable of achieving any goal that they set for their selves in the condition of giving it what it takes to accomplish that. The students were encouraged and motivated to be immersed in that experience of keep on practicing until they achieve the requirements. When we reflect back on our path through the last four months we feel very proud of what we accomplished and the information we learned.

At the end, the new model helped the students to generate connecting paths to their future careers through the involvement in the development stages of the learning process. They walked away with an enriched experience, sense of pride and that will help them in setting their future career paths. The students had a valuable learning experience and they will thrive on for a long time. We were able to created in students the passion to be a long life learners.

We generated connecting paths to their future careers through the involvement in the development stages. They walked away with an enriched experience that will help them in setting their future career paths.

\section{Acknowledgements}

The authors wish to thank the Learning and Teaching Centre (LTC) at the University of Victoria for the Curriculum Development Grant. The ENGR 141 Instructional Team, and the ENGR 141 Spring 2014 Cohort Students.

\section{References}

[1] ISW Network. Recourses, Instructional Skills Workshop (ISW) and Facilitator Development Workshop (FDW) Handbooks, Retrieved on April 1, 2014 from www.iswnetwork.ca.

[2] John Biggs and Catherine Tang, Teaching for quality learning at university. Fourth edition. Berkshire, England: Open University Press. McGraw Hill, 2011, 382 pp.

[3]Day, R., \& the ISW International Advisory Committee. (2005). The Instructional Skills Workshop: The heart of an educator learning community in British Columbia and beyond. Paper presented at the International Society for the Scholarship of Teaching and Learning Conference. Retrieved from http://iswnetwork.ca/wpcontent/uploads/2012/07/Hand_ISW_ISSoTL1.pdf 
[4]Kolb, D. A. Experiential learning: Experience as the source of learning and development. New Jersey: Prentice-Hall, 1984.

[5] David A. Lieberman. Human Learning and Memory.

Cambridge University Press, 2011.

[6] Anne Brockbank and Ian McGill, Facilitating Reflective Learning in Higher Education. Second edition. Berkshire, England: Open University Press. McGraw Hill, 2007, 368 pp.

[7] R.C. Hibbeler, Engineering Mechanics, thirteen edition. Berkshire, England: Open University Press. McGraw Hill, 2011, $382 \mathrm{pp}$.

[8]Pratt, D., \& Collins, J. (2013). TPI: Teaching Perspectives Inventory. Retrieved from http://www.teachingperspectives.com 